\title{
Long-term prognostic value of coronary computed tomography angiography for asymptomatic patients with CAD in type 2 diabetes mellitus
}

\author{
PEIGANG TIAN ${ }^{1}$, XIANGYANG ZHENG ${ }^{1}$, MINGZHI LI $^{1}$, WEIWEI LI $^{2}$ and QINGLIANG NIU ${ }^{1}$ \\ ${ }^{1}$ Imaging Center, Weifang Traditional Chinese Hospital, Weifang, Shandong 261000; \\ ${ }^{2}$ Department of Radiology, Tai'an Central Hospital Branch, Tai'an, Shandong 271000, P.R. China
}

Received June 16, 2018; Accepted January 18, 2019

DOI: $10.3892 /$ etm.2019.7593

\begin{abstract}
The present study was performed to investigate the prognostic value of coronary computed tomography angiography (CTA) results for asymptomatic patients with coronary artery disease (CAD) in type 2 diabetes mellitus (T2DM). A total of 164 asymptomatic patients with T2DM were enrolled at Weifang Traditional Chinese Hospital (Weifang, China). Coronary plaques and stenosis severity were evaluated after CTA. Structures $>1 \mathrm{~mm}^{2}$ adjacent to or within the coronary artery lumen that could be clearly separated from the vessel lumen, was scored as a coronary plaque. Stenosis of $\geq 50 \%$ was considered as being obstructive. CAD was defined as the presence of any coronary plaque or a coronary artery calcium (CAC) score of $>0$. A CAC score of 0 and no coronary plaques was considered to indicate the absence of CAD. A 5-year follow-up was performed to determine the impact of the CTA findings and various clinicopathological characteristics on the prognosis of all participants. The primary end-point was any cardiac event. Event-free survival curves were plotted using the Kaplan-Meier method and compared using the log-rank test. Based on the coronary CTA results, the patients were classified into 3 groups according to the extent of stenosis: Normal coronary arteries, obstructive CAD and non-obstructive CAD. Significant differences in 5-year event-free survival were identified among the groups with normal coronary arteries, non-obstructive CAD and obstructive $\mathrm{CAD}(\mathrm{P}=0.026)$. Further analysis indicated that the event-free survival rate of patients with 1-vessel CAD was $94.11 \%$, that of patients with 2-vessel CAD was $73.68 \%$ and that associated with 3 -vessel CAD was $61.54 \%$. Multivariate Cox regression analysis revealed that non-obstructive as
\end{abstract}

Correspondence to: Dr Qingliang Niu, Imaging Center, Weifang Traditional Chinese Hospital, 1055 Weizhou Road, Kuiwen, Weifang, Shandong 261000, P.R. China

E-mail:nnq105@126.com

Key words: coronary computed tomography angiography, coronary artery disease, type 2 diabetes mellitus, prognosis well as obstructive CAD diagnosed by coronary CTA are prognostic indicators for asymptomatic T2DM patients [hazard ratio $(\mathrm{HR})=11.132,95 \%$ confidence interval $(\mathrm{CI})$ : 1.857-66.742, $\mathrm{P}=0.008 ; \mathrm{HR}=7.792$, 95\% CI: $1.750-34.698$, $\mathrm{P}=0.007$, respectively]. In conclusion, the present study suggests that coronary CTA may predict the prognosis of asymptomatic patients with T2DM.

\section{Introduction}

The prevalence of diabetes mellitus (DM) has been rapidly increasing due to an aging population, urbanization, physical inactivity and obesity (1). An estimated 200 million individuals are affected by DM worldwide (2). Coronary artery disease (CAD) is the major cause of death in patients with DM. Affected patients are frequently asymptomatic regarding CAD until the development of myocardial infarction or sudden cardiac death (3). CAD is usually significantly more advanced in patients with DM at the time-point of diagnosis $(4,5)$. Its asymptomatic presentation and aggressiveness have made CAD the most common cause of death in patients with DM (6).

Non-invasive imaging methods for the detection of CAD have evolved rapidly over the past decades. With the advance of multidetector row computed tomography (CT), coronary CT angiography (CTA) has been effective in providing information on the extent and morphology of CAD, including disease severity, lesion location and characteristics of atherosclerotic plaques (7). It has been extensively validated that the combination of CTA with coronary calcium scoring is sensitive and specific in detecting CAD (8). Since CAD is frequently asymptomatic in patients with DM, coronary CTA may be applied to decrease cardiovascular morbidity and mortality through the early detection of CAD in DM patients at risk. CAD-associated CTA findings in patients with asymptomatic DM were reported to be associated with a higher risk of cardiac events (9-11).

Previous studies have investigated the association between DM and the risk of CAD among diabetic patients undergoing coronary CTA (12). However, only few studies have analyzed the prognostic role of CTA in Chinese patients with DM that are asymptomatic regarding CAD. The present 
study assessed the prognostic role of coronary CTA in Chinese patients with type $2 \mathrm{DM}$ (T2DM) who exhibited no symptoms of CAD.

\section{Materials and methods}

Subjects. A total of 164 Chinese T2DM patients that were asymptomatic regarding CAD and underwent coronary CTA at the Weifang Traditional Chinese Hospital (Weifang, China) between January 2011 and March 2012 were enrolled in the present study. T2DM was confirmed according to the criteria of the American Diabetes Association (13). Glycated hemoglobin (HbA1c) levels of $\geq 6.5 \%$, fasting blood glucose levels of $\geq 126 \mathrm{mg} / \mathrm{dl}$ and/or a post-challenge blood glucose level of $\geq 200 \mathrm{mg} / \mathrm{dl}$ ( $2 \mathrm{~h}$ after a 75 -g oral glucose load). The asymptomatic status of the subjects was evaluated using the Rose questionnaire for angina (14). Patients without CAD were defined as asymptomatic.

A structured interview was performed by a physician prior to the study to record the demographic and clinical data. Hypertension was defined as a systolic blood pressure of $\geq 140 \mathrm{mmHg}$ and/or a diastolic blood pressure of $\geq 90 \mathrm{mmHg}$, or the use of anti-hypertensive medication (15). Dyslipidemia was defined as ongoing treatment with lipid-lowering medications at the time of examination, or known but untreated dyslipidemia. The exclusion criteria were as follows: i) T1 diabetes; ii) known or suspected CAD; iii) abnormal resting electrocardiographic results; iv) history of prior myocardial infarction, coronary revascularization or heart failure; v) history of allergy to iodinated contrast. The present study was approved by the Review Board of Weifang Traditional Chinese Hospital (Weifang, China) and written informed consent was provided by all patients.

Coronary CTA. Scans were analyzed by two experienced radiologists. All examinations were performed using the Sensation 64 Slice CT scanner (Siemens AG, Munich, Germany). The coronary artery calcium (CAC) score was calculated using the Agatston method (16). Coronary CTA was performed using the electrocardiogram-gated protocol: Detector collimation $64(32 \times 2) \times 0.6 \mathrm{~mm}, 80-120 \mathrm{kV}$ assessed according to the patient's body habitus, $240-400 \mathrm{~mA} /$ rotation according to the patient's body habitus, rotation time of $0.33 \mathrm{sec}$, radiation dose of $8-13 \mathrm{mSv}$, pitch value of $0.2-0.5$ according to the patient's heart rate. Next, $55-80 \mathrm{ml}$ iodine (400 mg/ml; Iomeron; Bracco Imaging SpA, Milan, Italy) was injected at $4-6 \mathrm{ml} / \mathrm{sec}$.

Coronary arteries were divided into 18 segments following the Society of Cardiovascular Computed Tomography guidelines (14). Each segment was examined for coronary plaques. Structures of $>1 \mathrm{~mm}^{2}$ adjacent to or within the coronary artery lumen that could be clearly separated from the vessel lumen, was scored as a coronary plaque (17). Each coronary segment was scored individually for the presence of plaque and stenosis was visually quantified. The severity of stenosis was categorized as follows: <25, 25-49, 50-69, 70-99 and $100 \%$. A stenosis of $\geq 50 \%$ was considered obstructive. CAD was defined as the presence of any coronary plaques or a CAC score of $>0$. A CAC score of 0 and no coronary plaques signified the absence of CAD.
End-points and follow-up. Medical treatments, including the administration of anti-hypertensive agents, statins and anti-diabetic agents, were continued during the acquisition of the data for the present study. The primary end-point was time to occurrence of any cardiac event. A cardiac event was defined as a composite of non-fatal myocardial infarction, unstable angina that required hospitalization, cardiac death and late coronary revascularization.

A 5-year follow-up was performed by a research nurse or dedicated physician. Any clinical events were determined by a phone and/or face-to-face interview with the patients, and/or based on their medical records.

Statistical analysis. Continuous variables are expressed as the mean \pm standard deviation. The differences in continuous variables among normal, non-obstructive and obstructive CAD groups were compared using one-way analysis of variance. A post-hoc test (Tukey's test) was performed to identify differences between two groups. Differences in categorical variables were assessed using the $\chi^{2}$ test. Event-free survival curves were plotted using the Kaplan-Meier method and compared using the log-rank test. Univariate and multivariate Cox regression analyses were performed to identify risk factors associated with cardiac events, including age, sex, duration of DM, body mass index, systolic and diastolic blood pressure, hypertension, smoking, family history of CAD, dyslipidemia, previous stroke, previous peripheral arterial disease, fasting blood glucose, HbAlc, creatinine, total cholesterol, low-density lipoprotein (LDL) cholesterol, high-density lipoprotein (HDL) cholesterol, triglycerides and anti-DM treatment. Hazard ratios (HR) with 95\% confidence intervals (CIs) were calculated to determine the prognostic factors for asymptomatic T2DM. $\mathrm{P}<0.05(\alpha=0.05)$ was considered to indicate a statistically significant difference. All statistical analyses were performed using SPSS 18.0 software (SPSS, Inc., Chicago, IL, USA).

\section{Results}

Demographic characteristics of subjects. Following coronary CTA, the patients were classified into three groups, according to the stenosis diameter: Normal coronary artery group, obstructive CAD group ( $\geq 50 \%$ stenosis) and non-obstructive CAD group ( $<50 \%$ stenosis). The detailed demographic information for all patients is listed in Table I. Significant differences were observed in age, sex, duration of DM, family history of CAD, previous stroke, total cholesterol, LDL cholesterol and triglycerides among the three groups (all $\mathrm{P}<0.05$ ). The mean age of patients in the normal, non-obstructive and obstructive CAD groups was $(56.80 \pm 5.43),(58.64 \pm 3.22)$ and $(60.61 \pm 2.72)$, respectively, and significant differences were observed in the age of patients among the three groups $(\mathrm{P}<0.001)$. The amount of males was 21 (38.89\%), $42(68.85 \%)$ and $31(63.26 \%)$ in the normal, non-obstructive and obstructive CAD groups, respectively, and significant differences were observed in the number of males among the three groups $(\mathrm{P}=0.003)$. The results also revealed significant differences in DM duration $(\mathrm{P}<0.001)$, hypertension $(\mathrm{P}=0.041)$, family history of $\mathrm{CAD}(\mathrm{P}=0.021)$, previous stroke $(\mathrm{P}<0.001)$, total cholesterol $(\mathrm{P}<0.001)$, LDL cholesterol $(\mathrm{P}<0.001)$ and triglyceride $(\mathrm{P}<0.001)$ among the normal, non-obstructive, and obstructive CAD groups. The 


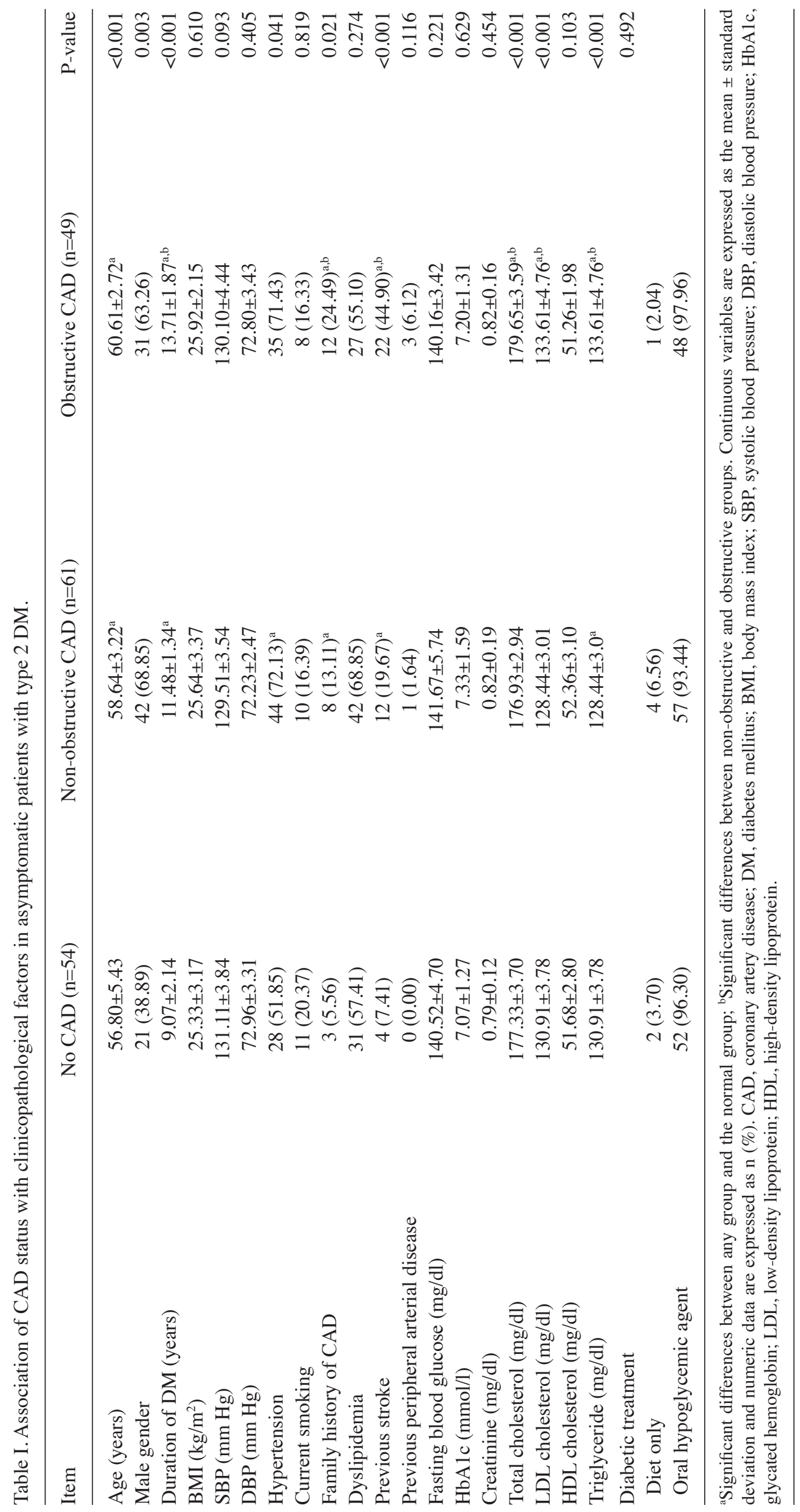


coronary CTA findings for all participants are presented in Table II.

Kaplan-Meier survival curves. During the 5-year follow-up, 20 cardiac events were recorded in the present study population ( 3 in the normal coronary artery, 6 in the non-obstructive CAD and 11 in the obstructive CAD group). The Kaplan-Meier curves indicated significant differences in the event-free survival among the groups ( $\mathrm{P}=0.026$; Fig. 1$)$.

The patients with obstructive CAD comprised 17 patients with 1-vessel CAD, 19 with 2-vessel CAD and 13 with 3-vessel CAD. The survival rate of patients with 1-, 2- and 3-vessel CAD was analyzed (Fig. 2). The event-free survival rate of patients with 1-vessel CAD was $94.11 \%$, that of patients with 2-vessel CAD was $73.68 \%$ and that of patients with 3-vessel CAD was $61.54 \%$. The results indicated that the prognosis of patients with 1-vessel CAD was better compared with that of patients with 2- and 3-vessel CAD ( $\mathrm{P}=0.003)$.

Multivariate Cox analysis. The results of multivariate Cox analysis are presented in Table III. It was observed that HDL cholesterol $(\mathrm{HR}=1.242,95 \% \mathrm{CI}: 1.024-1.507, \mathrm{P}=0.028)$ and triglycerides $(\mathrm{HR}=1.256,95 \% \mathrm{CI}: 1.113-1.416, \mathrm{P}<0.001)$ were independent prognostic factors in patients with asymptomatic T2DM. The presence of non-obstructive and obstructive CAD was indicated to be associated with the prognosis of patients with asymptomatic T2DM $(\mathrm{HR}=11.132,95 \% \mathrm{CI}$ : 1.857-66.742, $\mathrm{P}=0.008 ; \mathrm{HR}=7.792$, 95\% CI: 1.750-34.698, $\mathrm{P}=0.007$, respectively).

\section{Discussion}

T2DM, a chronic metabolic disease, is a major health concern, as it affects $>382$ million individuals worldwide (18). CAD is the major cause of death among patients with T2DM $(19,20)$. Population-based studies have reported a 2- to 4-fold frequency in the number of cardiovascular events experienced by patients with T2DM $(21,22)$. The diagnosis of CAD is commonly missed or delayed, since the symptoms of CAD are usually absent in patients with T2DM, which in turn enhances the risk for cardiovascular events.

Invasive coronary angiography (ICA) is considered the gold standard for detecting the presence, localization and severity of CAD. However, it is an invasive method associated with complications. Furthermore, the procedural cost is substantial. Coronary CTA is a recently introduced alternative to ICA for the detection of CAD, and 64-slice multidetector CT has been found highly effective in the diagnosis of significant coronary stenosis (23). Liu et al (24) performed a CTA study in 150 T2DM patients with a follow-up of $\geq 2$ years and the results suggested that CTA may be used as a non-invasive modality for predicting high-risk CAD in patients with T2DM. A cross-sectional study by Ulimoen et al (25) indicated that coronary CTA had a high sensitivity (100\%) and a negative predictive value (100\%) for detecting CAD, suggesting that it is a reliable method for detecting significant CAD in T2DM and may prove useful to clinicians. However, few studies have investigated the prognostic role of CTA in Chinese T2DM patients that are asymptomatic regarding CAD.
Table II. Coronary computed tomography angiography findings for all participants.

\begin{tabular}{lc}
\hline Item & Value \\
\hline CAC score & $91(0-38)$ \\
Any plaque & $88(53.6)$ \\
Plaque characteristics & \\
Calcified & $58(35.4)$ \\
Non-calcified & $61(37.2)$ \\
Mixed & $45(27.4)$ \\
Severity of CAD & \\
No CAD & $54(32.9)$ \\
Non-obstructive CAD & $61(37.2)$ \\
Obstructive CAD & $49(29.9)$ \\
Number of vessels with obstructive CAD lesions & \\
1 & $17(34.7)$ \\
2 & $19(38.8)$ \\
3 & $13(26.5)$ \\
High-risk CAD & $21(12.8)$ \\
Segment involvement score & $2.36 \pm 0.87$ \\
Segment stenosis score & $2.29 \pm 0.96$ \\
Modified Duke prognostic score & $1.48 \pm 0.68$ \\
\hline
\end{tabular}

Values are expressed as the median (interquartile range), $\mathrm{n}(\%)$ or the mean \pm standard deviation. CAC, coronary artery calcium; CAD, coronary artery disease.

CTA provides detailed information on the morphology and extent of CAD. The advantage of CTA is that it may be used to exclude CTA in patients with a low-to-intermediate cardiovascular risk, which is broadly endorsed by international societies (26). Due to improvements in CTA technology, the radiation dose per patient has been decreased to acceptable levels. Sub-millisievert (mSv) scans with the latest generation scanners use effectives dose of $<1.0 \mathrm{mSv}$ without compromising the imaging quality (27). The Coronary Artery Evaluation Using 64-Row Multidetector CTA study identified a significant correlation between CTA and ICA when testing the extent and severity of CAD (28); this resulted in the extensive clinical application of CTA. Fujimoto et al (29) reported that the evaluation of CTA plaque characteristics may provide an incremental prognostic value to the number of diseased vessels and the Framingham risk score (FRS). This evidence suggests a predictive role of CTA for CAD. Blanke et al (30) reported that among patients with DM, non-obstructive and obstructive CAD, as determined by coronary CTA, were associated with higher rates of all-cause mortality and major adverse cardiovascular events at 5 years.

In the present study, 164 patients with asymptomatic T2DM were enrolled, and CTA was performed to detect coronary stenosis in all of them. The patients were classified into three groups, based on the coronary CTA results: Normal coronary artery group, obstructive CAD group $(\geq 50 \%$ stenosis) and non-obstructive CAD group ( $<50 \%$ stenosis). 


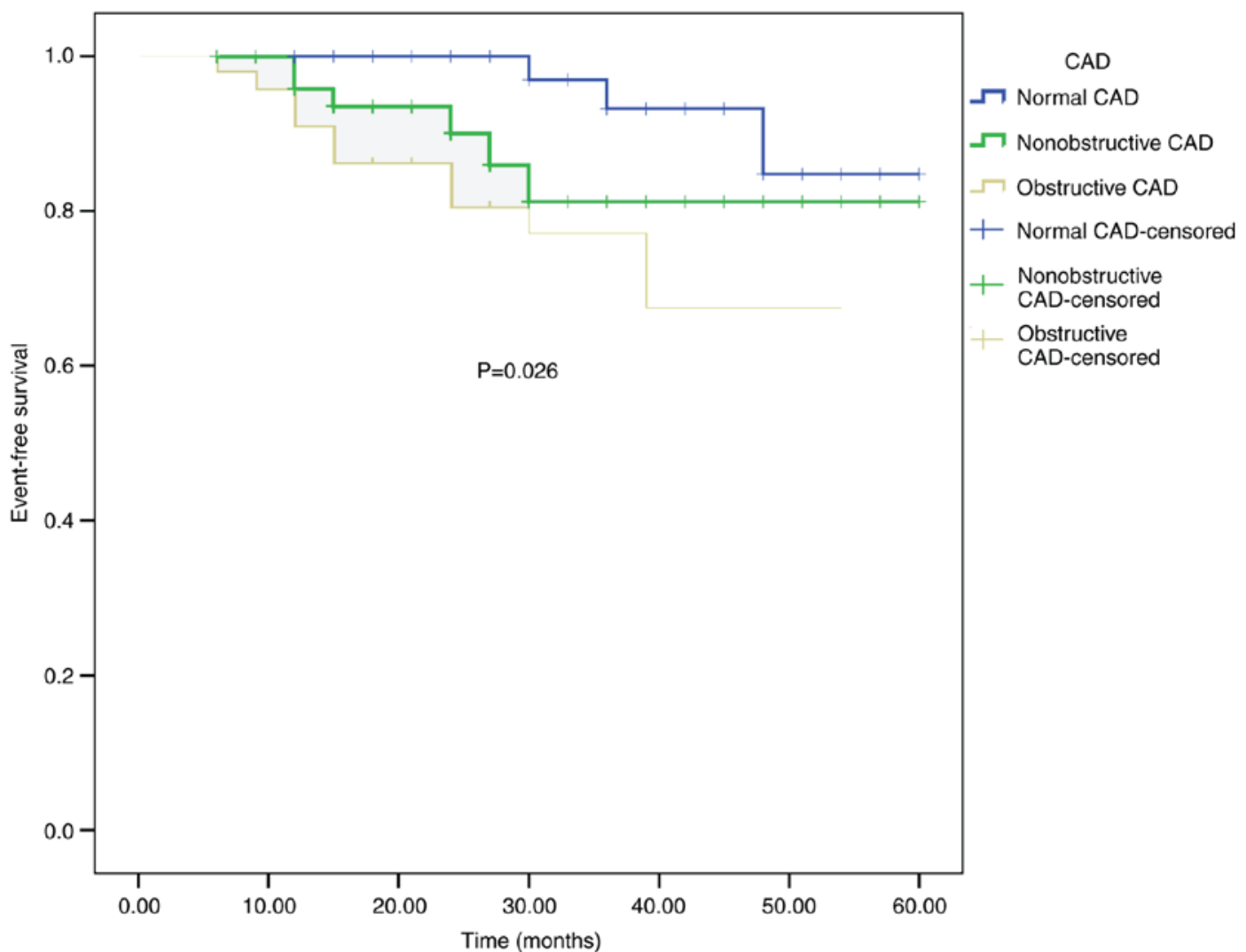

Figure 1. Event-free survival of participants with normal coronary arteries, non-obstructive CAD and obstructive CAD. Kaplan-Meier curves exhibited significant differences in event-free survival among groups with normal coronary arteries, non-obstructive $\mathrm{CAD}$ and obstructive $\mathrm{CAD}$ ( $\mathrm{P}=0.026$ according to log-rank test). CAD, coronary artery disease.

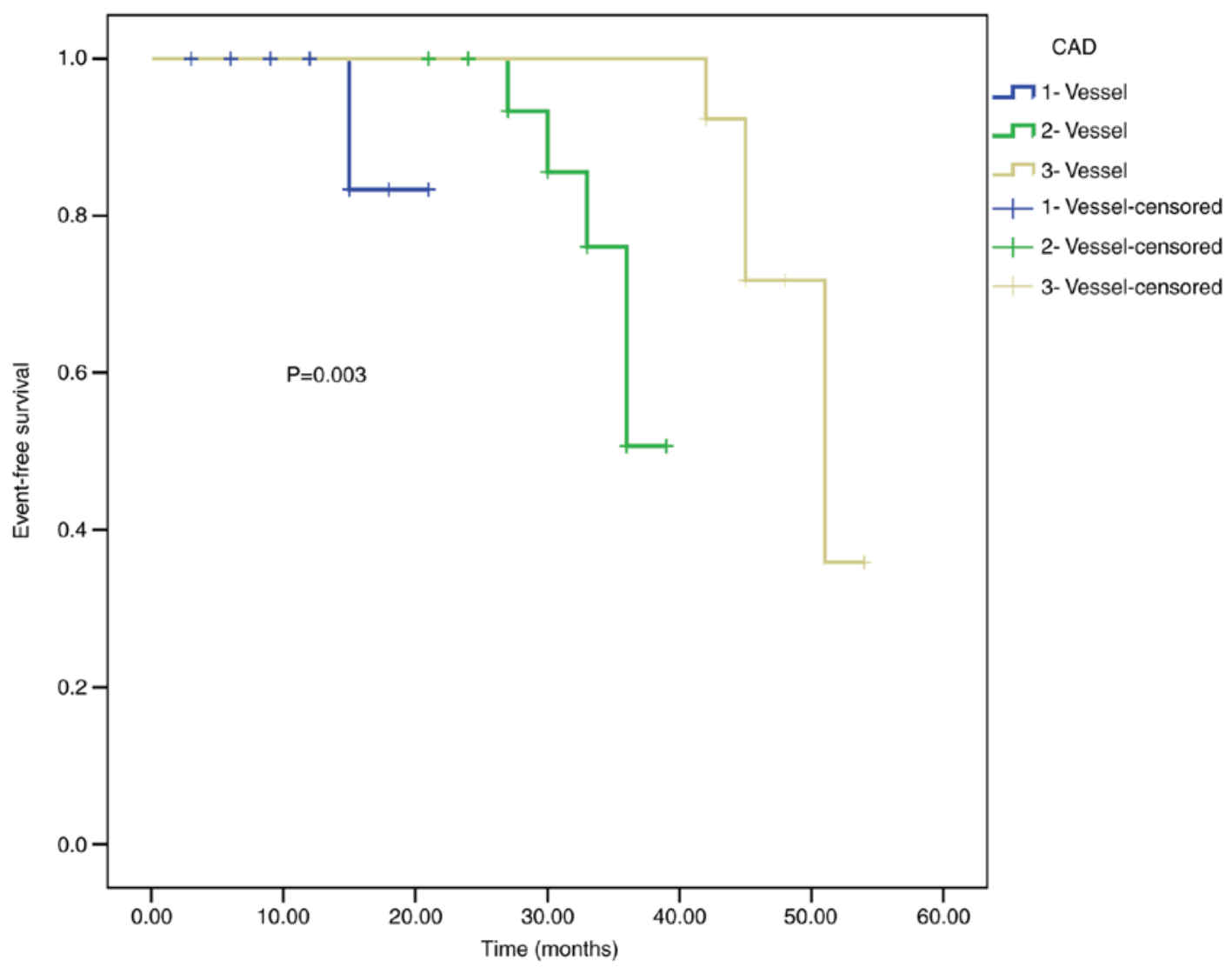

Figure 2. Event-free survival of participants with 1-vessel CAD, 2-vessel CAD and 3-vessel CAD. The results indicated that the prognosis of patients with 1-vessel CAD was better than that in patients with 2-vessel and 3-vessel CAD ( $\mathrm{P}=0.003$ according to log-rank test). CAD, coronary artery disease. 
Table III. Uni- and multivariate Cox regression analysis of the prognostic biomarkers for asymptomatic patients with type 2 diabetes mellitus.

\begin{tabular}{lcrr}
\hline A, Univariate analysis & & & \\
\hline Factor & HR & $95 \%$ CI & P-value \\
\hline Sex (male vs. female) & 2.053 & $1.040-4.053$ & 0.038 \\
Duration of DM $(>14$ years vs. $<14$ years) & 1.214 & $1.027-1.436$ & 0.023 \\
BMI $(>26$ vs. $<26)$ & 1.458 & $1.189-1.787$ & $<0.001$ \\
SBP $(>131 \mathrm{mmHg}$ vs. $<131 \mathrm{mmHg})$ & 1.179 & $1.081-1.285$ & $<0.001$ \\
DBP $(>74 \mathrm{mmHg}$ vs. $<74 \mathrm{mmHg})$ & 1.323 & $1.148-1.525$ & $<0.001$ \\
HbA1c $(>7 \mathrm{mmol} / \mathrm{l}$ vs. $<7 \mathrm{mmol} / \mathrm{l})$ & 1.573 & $1.165-2.124$ & 0.003 \\
Total cholesterol $(>179 \mathrm{mg} / \mathrm{dl}$ vs. $<179 \mathrm{mg} / \mathrm{dl})$ & 0.805 & $0.739-0.878$ & $<0.001$ \\
Triglyceride $(>134 \mathrm{mg} / \mathrm{dl}$ vs. $<134 \mathrm{mg} / \mathrm{dl})$ & 1.427 & $1.251-1.627$ & $<0.001$ \\
CTA finding & & & 0.010 \\
Non-obstructive CAD vs. no CAD & 23.580 & $21.251-34.854$ & 0.022 \\
Obstructive CAD vs. no CAD & 17.526 & $14.852-28.413$ & \\
\hline
\end{tabular}

B, Multivariate analysis

\begin{tabular}{lccr}
\hline Factor & HR & $95 \%$ CI & P-value \\
\hline Sex (male vs. female) & 1.241 & $0.711-2.058$ & 0.324 \\
Duration of DM $(>14$ years vs. $<14$ years $)$ & 0.853 & $0.747-1.259$ & 0.114 \\
BMI $(>26$ vs. $<26)$ & 0.910 & $0.779-1.335$ & 0.147 \\
SBP $(>131 \mathrm{mmHg}$ vs. $<131 \mathrm{mmHg})$ & 0.887 & $0.698-1.117$ & 0.139 \\
DBP $(>74 \mathrm{mmHg}$ vs. $<74 \mathrm{mmHg})$ & 0.696 & $0.559-1.084$ & 0.215 \\
HbAlc $(>7 \mathrm{mmol} / \mathrm{l}$ vs. $<7 \mathrm{mmol} / \mathrm{l})$ & 1.178 & $0.947-1.568$ & 0.365 \\
Total cholesterol $(>179 \mathrm{mg} / \mathrm{dl} \mathrm{vs.}<179 \mathrm{mg} / \mathrm{dl})$ & 0.442 & $0.325-1.479$ & 0.541 \\
HDL $(>52 \mathrm{mg} / \mathrm{dl}$ vs. $<52 \mathrm{mg} / \mathrm{dl})$ & 1.242 & $1.024-1.507$ & 0.028 \\
Triglyceride $(>134 \mathrm{mg} / \mathrm{dl}$ vs. $<134 \mathrm{mg} / \mathrm{dl})$ & 1.256 & $1.113-1.416$ & $<0.001$ \\
CTA finding & & & 0.008 \\
Non-obstructive CAD vs. no CAD & 11.132 & $1.857-66.742$ & 0.007 \\
Obstructive CAD vs. no CAD & 7.792 & $1.750-34.698$ & \\
\hline
\end{tabular}

HR, hazard ratio; CI, confidence interval; HDL, high-density lipoprotein; CTA, computed tomography angiography; CAD, coronary artery disease.

Significant differences in age, sex, duration of DM, family history of CAD, previous stroke, total cholesterol, LDL cholesterol and triglycerides were observed among the three groups (all $\mathrm{P}<0.05$ ). After a 5-year follow-up, 20 events were observed in the study population ( 3 for normal coronary artery, 6 for the non-obstructive CAD and 11 for the obstructive CAD group). The Kaplan-Meier curve indicated that the event-free survival of subjects in the normal coronary artery group was the highest among all participants $(\mathrm{P}=0.026)$. This result was consistent with the study by Kang et al (31), which revealed that asymptomatic patients with T2DM and normal coronary arteries, non-obstructive CAD or coronary CTA exhibit excellent clinical outcomes over a follow-up period of $>5$ years, whereas prognosis is worse in patients with obstructive CAD (30). Further Cox analysis demonstrated that non-obstructive and obstructive CAD may serve as prognostic indicators for T2DM patients that are asymptomatic. In addition, it was revealed that the event-free survival rate in patients with 1-vessel CAD was $94.11 \%$, that in patients with 2-vessel CAD was $73.68 \%$ and that associated with 3-vessel CAD was $61.54 \%$, indicating that the prognosis of patients with 1-vessel CAD was better compared with that of patients with 2- and 3-vessel CAD ( $\mathrm{P}=0.003)$.

The results of the present study demonstrated that coronary CTA testing may predict the prognosis of asymptomatic T2DM patients. However, the present study had limitation: the sample size was relatively small. Large-scale studies should be performed in the future to confirm these results. Furthermore, only Chinese patients examined at one hospital were enrolled in the present study, and multiple-center studies are required to validate the present results.

In conclusion, the results of coronary CTA may serve as prognostic indicators for asymptomatic T2DM patients. The event-free survival of patients with normal coronary arteries 
was markedly higher compared with that of patients with non-obstructive and obstructive CAD. Furthermore, the prognosis of patients with 1-vessel CAD is better compared with that of patients with 2- and 3-vessel CAD.

\section{Acknowledgements}

Not applicable.

\section{Funding}

No funding was received.

\section{Availability of data and materials}

All the datasets generated and analyzed in the present study are included in this published manuscript/are available from the corresponding author on reasonable request.

\section{Authors' contributions}

QN designed the current study. PT, XZ and ML performed the experiments. PT, MZL and WL analyzed the data. PT and XZ drafted the manuscript. ML, WL, and QN revised the manuscript.

\section{Ethics approval and consent to participate}

The present study was approved by the ethics committee of Weifang Traditional Chinese Hospital (Weifang, China). Written informed consent was provided by all patients.

\section{Patient consent for publication}

Not applicable.

\section{Competing interests}

The authors declare that they have no competing interests.

\section{References}

1. King H, Aubert RE and Herman WH: Global burden of diabetes, 1995-2025: Prevalence, numerical estimates, and projections. Diabetes Care 21: 1414-1431, 1998.

2. International diabetes federation: International diabetes federation, 2013.

3. Young LH, Wackers FJ, Chyun DA, Davey JA, Barrett EJ, Taillefer R, Heller GV, Iskandrian AE, Wittlin SD, Filipchuk N, et al: Cardiac outcomes after screening for asymptomatic coronary artery disease in patients with type 2 diabetes: The DIAD study: A randomized controlled trial. JAMA 301: $1547-1555,2009$

4. Goraya TY, Leibson CL, Palumbo PJ, Weston SA, Killian JM, Pfeifer EA, Jacobsen SJ, Frye RL and Roger VL: Coronary atherosclerosis in diabetes mellitus: A population-based autopsy study. J Am Coll Cardiol 40: 946-953, 2002.

5. Hu FB, Stampfer MJ, Haffner SM, Solomon CG, Willett WC and Manson JE: Elevated risk of cardiovascular disease prior to clinical diagnosis of type 2 diabetes. Diabetes Care 25: 1129-1134, 2002 .

6. Grundy SM, Benjamin IJ, Burke GL, Chait A, Eckel RH, Howard BV, Mitch W, Smith SC Jr and Sowers JR: Diabetes and cardiovascular disease: A statement for healthcare professionals from the American heart association. Circulation 100: 1134-1146, 1999.
7. Park GM, Lee SW, Cho YR, Kim CJ, Cho JS, Park MW, Her SH, Ahn JM, Lee JY, Park DW, et al: Coronary computed tomographic angiographic findings in asymptomatic patients with type 2 diabetes mellitus. Am J Cardiol 113: 765-771, 2014.

8. Petcherski O, Gaspar T, Halon DA, Peled N, Jaffe R, Molnar R, Lewis BS and Rubinshtein R: Diagnostic accuracy of 256-row computed tomographic angiography for detection of obstructive coronary artery disease using invasive quantitative coronary angiography as reference standard. Am J Cardiol 111: 510-515, 2013.

9. Andreini D, Pontone G, Mushtaq S, Bertella E, Conte E, Baggiano A, Veglia F, Agostoni P, Annoni A, Formenti A, et al: Prognostic value of multidetector computed tomography coronary angiography in diabetes: Excellent long-term prognosis in patients with normal coronary arteries. Diabetes Care 36: 1834-1841, 2013.

10. Cho I, Chang HJ, Sung JM, Pencina MJ, Lin FY, Dunning AM, Achenbach S, Al-Mallah M, Berman DS, Budoff MJ, et al: Coronary computed tomographic angiography and risk of all-cause mortality and nonfatal myocardial infarction in subjects without chest pain syndrome from the CONFIRM Registry (coronary CT angiography evaluation for clinical outcomes: An international multicenter registry). Circulation 126: 304-313, 2012.

11. Hadamitzky M, Hein F, Meyer T, Bischoff B, Martinoff S, Schömig A and Hausleiter J: Prognostic value of coronary computed tomographic angiography in diabetic patients without known coronary artery disease. Diabetes Care 33: 1358-1363, 2010.

12. Krul MM, Bogaard K, Knol RJ, van Rossum AC, Knaapen P, Cornel JH and van der Zant FM: Coronary artery disease in patients with atypical chest pain with and without diabetes mellitus assessed with coronary CT angiography. BMJ Open Diabetes Res Care 2: e000004, 2014.

13. American Diabetes Association: Diagnosis and classification of diabetes mellitus. Diabetes Care 33 (Suppl 1): S62-S69, 2010.

14. Raff GL, Abidov A, Achenbach S, Berman DS, Boxt LM, Budoff MJ, Cheng V, DeFrance T, Hellinger JC and Karlsberg RP; Society of Cardiovascular Computed Tomography: SCCT guidelines for the interpretation and reporting of coronary computed tomographic angiography. J Cardiovasc Comput Tomogr 3: 122-136, 2009.

15. European Society of Hypertension-European Society of Cardiology Guidelines Committee: 2003 European society of hypertension european society of cardiology guidelines for the management of arterial hypertension. J Hypertens 21: 1011-1053, 2003.

16. Agatston AS, Janowitz WR, Hildner FJ, Zusmer NR, Viamonte $\mathrm{M} \mathrm{Jr}$ and Detrano R: Quantification of coronary artery calcium using ultrafast computed tomography. J Am Coll Cardiol 15: 827-832, 1990.

17. Choo EH, Kim JJ, Hwang BH, Choi IJ, Chang M, Lim S, Koh Y, Park HJ, Kim PJ, Lee SH, et al: Status of hypertension and coronary stenosis in asymptomatic type 2 diabetic patients: Analysis from coronary computed tomographic angiography registry. Int J Cardiol 174: 282-287, 2014.

18. IDF Diabetes Atlas 6th Edition. International Diabetes Federation, Brussels, 2013. www.idf.org/diabetesatlas.

19. Lorber D: Importance of cardiovascular disease risk management in patients with type 2 diabetes mellitus. Diabetes Metab Syndr Obes 7: 169-183, 2014.

20. Stamler J, Vaccaro O, Neaton JD and Wentworth D: Diabetes, other risk factors, and 12-yr cardiovascular mortality for men screened in the multiple risk factor intervention trial. Diabetes Care 16: 434-444, 1993.

21. Becker A, Bos G, de Vegt F, Kostense PJ, Dekker JM, Nijpels G, Heine RJ, Bouter LM and Stehouwer CD: Cardiovascular events in type 2 diabetes: Comparison with nondiabetic individuals without and with prior cardiovascular disease. 10-year follow-up of the Hoorn study. Eur Heart J 24: 1406-1413, 2003.

22. Schramm TK, Gislason GH, Køber L, Rasmussen S, Rasmussen JN, Abildstrøm SZ, Hansen ML, Folke F, Buch P, Madsen M, et al: Diabetes patients requiring glucose-lowering therapy and nondiabetics with a prior myocardial infarction carry the same cardiovascular risk: A population study of 3.3 million people. Circulation 117: 1945-1954, 2008.

23. Janne d'Othée B, Siebert U, Cury R, Jadvar H, Dunn EJ and Hoffmann U: A systematic review on diagnostic accuracy of CT-based detection of significant coronary artery disease. Eur J Radiol 65: 449-461, 2008 
24. Liu D, Jia H, Liu W, Ma D, Tan G, He W, Fu Y and Wang LX: Value of multi-detector computed tomography angiography in predicting acute cardiac events in patients with type 2 diabetes. Exp Ther Med 7: 917-922, 2014.

25. Ulimoen GR, Ofstad AP, Endresen K, Gullestad L, Johansen OE and Borthne A: Low-dose CT coronary angiography for assessment of coronary artery disease in patients with type 2 diabetes-a cross-sectional study. BMC Cardiovasc Disord 15: 147, 2015.

26. Taylor AJ, Cerqueira M, Hodgson JM, Mark D, Min J, O'Gara P, Rubin GD; American College of Cardiology Foundation Appropriate Use Criteria Task Force; Society of Cardiovascular Computed Tomography; American College of Radiology, et al: ACCF/SCCT/ACR/AHA/ASE/ASNC/NASCI/SCAI/SCMR 2010 appropriate use criteria for cardiac computed tomography. A report of the American College of Cardiology Foundation Appropriate Use Criteria Task Force, the Society of Cardiovascular Computed Tomography, the American College of Radiology, the American Heart Association, the American Society of Echocardiography, the American Society of Nuclear Cardiology, the North American society for cardiovascular imaging, the society for cardiovascular angiography and interventions, and the society for cardiovascular magnetic resonance. J Am Coll Cardiol 56: 1864-1894, 2010.
27. Achenbach S, Marwan M, Ropers D, Schepis T, Pflederer T, Anders K, Kuettner A, Daniel WG, Uder M and Lell MM: Coronary computed tomography angiography with a consistent dose below $1 \mathrm{mSv}$ using prospectively electrocardiogram-triggered high-pitch spiral acquisition. Eur Heart J 31: 340-346, 2010.

28. Miller JM, Rochitte CE, Dewey M, Arbab-Zadeh A, Niinuma H, Gottlieb I, Paul N, Clouse ME, Shapiro EP, Hoe J, et al: Diagnostic performance of coronary angiography by 64-row CT. N Engl J Med 359: 2324-2336, 2008.

29. Fujimoto S, Kondo T, Takamura K, Baber U, Shinozaki T, Nishizaki Y, Kawaguchi Y, Matsumori R, Hiki M, Miyauchi K, et al: Incremental prognostic value of coronary computed tomographic angiography high-risk plaque characteristics in newly symptomatic patient. J Cardiol 67: 538-544, 2016.

30. Blanke P, Naoum C, Ahmadi A, Cheruvu C, Soon J, Arepalli C, Gransar H, Achenbach S, Berman DS, Budoff MJ, et al: In the present study, we enrolled 164 asymptomatic patients with T2DM and performed CTA to detect coronary stenosis on all of them. JACC Cardiovasc Imaging 9: 1280-1288, 2016.

31. Kang SH, Park GM, Lee SW, Yun SC, Kim YH, Cho YR, Park HW, Suh J, Yang DH, Kang JW, et al: Long-term prognostic value of coronary CT angiography in asymptomatic type 2 diabetes mellitus. JACC Cardiovasc Imaging 9: 1292-1300, 2016. 